\title{
Using a Hashin Criteria to predict the Damage of composite notched plate under traction and torsion behavior
}

\author{
Fouzia Larbi Chaht, Mohamed Mokhtari, Habib Benzaama \\ Ecole Nationale Polytechnique Maurice Audin, Algeria \\ fouzialose@hotmail.com,mokhtarimohamed44@yahoo.fr,Habenza@yahoo.fr
}

\begin{abstract}
The volume fraction effect of carbon fiber in an epoxy matrix in the vicinity of the notch on the traction and torsion behavior were studied. This volume fraction which increases with the reduction of the thickness is a parameter which proved effective on the capacity of resistance. The calculations are done with the numerical code ABAQUS 2009 [1]. using the model Hashin with shell elements of the structure. The objective of this study is to simulate the damage of stratified composite materials, the effect of several parameters such as the stacking sequence and the increase of the thickness of the folds having the same orientation of the structure, were evaluated and presented by load-displacement curves. The results obtained from the study illustrate the variation of damage as a function of these effects which act simultaneously and which also show that these modifications have a higher absorption capacity than that without modifications.
\end{abstract}

KEYwORDS. FEM (Finite Element Method); Hashin criteria; Shell element; Reinforcement.

\section{OPEN ACCESS}

Citation: Larbi Chaht, F., Mokhtari, M., Benzaama, H., Using a Hashin Criteria to predict the Damage of composite notched plate under traction and torsion behavior, Frattura ed Integrità Strutturale, 50 (2019) 331-341.

Received: 16.05 .2019

Accepted: 18.08 .2019

Published: 01.10.2019

Copyright: (C) 2019 This is an open access article under the terms of the CC-BY 4.0 , which permits unrestricted use, distribution, and reproduction in any medium, provided the original author and source are credited.

\section{INTRODUCTION}

$\mathrm{T}$ he use of composite materials has been increasing since their appearance. This use is justified by many advantages, the most remarkable is the relationship between resistance and weight saving. Composite materials are an important research area (report 1989) [2], from which many researchers are attracted by the study of their damage [3]. This gives them special importance for the design, production, certification and monitoring of a growing variety of structures.

In laminates there is a diversity in the mechanisms of damage produced by several parameters. These parameters are probably affected by the presence of the notch which causes an imbalance of the resistance around their zones. Studies have been conducted by researchers to better characterize this phenomenon. Lu studied the phenomenon of concentration and distribution of stresses around a hole [4]. Subsequently, analytical solutions have been progressively developed by researchers for increasingly complex geometries. Madani [5] have greatly contributed to the knowledge and development of this field by performing a systematic analysis of the main geometries and shapes. 
Several researchers have studied the effect of the stacking sequence on the behavior of composite structures such as Mokhtari [6] and the use of stratified composite with change in ply thicknesses Mokhtari [7]. These techniques have been expanded by the use of strengthening or repair patch by Ait Kaci [8]and Benzaama [9].

In the damage the models are implemented on formulations of solid type Donado [10], and more often of the shell type, these two-dimensional elements Peter Linde [11] with a geometrically zero thickness are used for problems of thickness and displacement more or they can greatly reduce the calculation time Elangovan [12].But in the case where the shear deformation occurs in structures with a larger thickness, we must opt for the use of solid elements which give results that can't be obtained by shell elements Yong Guo [13]. on which rests a good accuracy.

The Hashin criterion Barberon [14] seen improvements in its prediction ability through the quadratic interaction criterion between the different tractions; that of the fiber and the matrix acting on the plane of damage until the introduction of the criteria which distinguish between the tension and the compression of fiber and the matrix, and this by using a quadratic interaction between stress invariants. According to the researchers, the latter is not always appropriate in the case of matrix or fiber compression, and which does not take into account the effects of shear in the plane which significantly reduces the compressive strength of a composite layer. This prompted several researchers to propose modifications to the Hashin criteria in order to improve their predictive abilities Carlos [15]. We use this Hashin damage criterion for unidirectional fiber composites: This is a criterion that interacts with more than one stress component to evaluate different fracture modes. This criterion was originally developed for unidirectional polymer composites, and other types of non-polymeric laminates. Failure indices for the Hashin criteria are related to fiber and die failures and involve four failure modes. The maximum stress criteria are used for the transverse normal stress component that respond to threedimensional problems.

Notches are inevitable in the design of structures. This is the problematic of our work because are the areas where the initiation and the propagation of the cracks will take place. This approach, which can practically be difficult to achieve, is approved by the numerical results and can also be a solution to other problems in composite structures. The originality of our work is the improvement of the resistance of a composite structure notched by modifications both geometric and others whose parameters of the material in use is the criterion of Haschin. This objective will take place if the architecture parameters of the composite are optimized because the competition between the reduction of thickness and the increase of the volume fraction of the fibers amply show results which are highly evaluative by their parameters.

\section{HASHING CRITERIA AND INPUT PARAMETER}

$\mathrm{T}$ he growth prediction and the damage trajectory are implemented by an intra-laminar damage criterion that is implemented in the standard Abaqus calculation code [16].

The input data for the Hashin criteria given in the tables are longitudinal tensile and compressive strengths, transverse tensile and compressive strengths, and longitudinal and transverse shear strengths. All resistance values are assumed to be positive Sokolinsky [17]. In this criterion of damage there is no inter-laminar propagation path, no separation or existence of the interface but the damage is continuous in the structure by degradation of rigidity or by removal of the elements of the structure.

Several modes of damage can occur such as the breaking of the fiber and that of the matrix in tension and in compression. In most of cases these modes occur simultaneously, hence the importance of opting for the Hashin criterion which introduces six criteria for initiation of tension and compression damage for fiber and matrix and at the interface level. This is to predict the multimodal phenomenon of composite damage. The Hashin criteria used are quadratic, not because of their mechanical behavior may be the fit of the curve Pederson [18]. These criteria of damage have the following general forms:

1. Tensile fiber failure for $\sigma_{11} \geq 0\left(\frac{\sigma_{11}}{X_{T}}\right)^{2}+\frac{\sigma_{12}^{2}+\sigma_{13}^{2}}{S_{12}^{2}}= \begin{cases}\geq 1 & \text { failure } \\ <1 & \text { no failure }\end{cases}$

2. Compressive fiber failure for $\sigma_{11}<0\left(\frac{\sigma_{11}}{X_{C}}\right)^{2}= \begin{cases}\geq 1 & \text { failure } \\ <1 & \text { no failure }\end{cases}$ 
3. Tensile matrix failure for $\sigma_{22}+\sigma_{33}>0 \frac{\left(\sigma_{22}+\sigma_{33}\right)^{2}}{Y_{T}^{2}}+\frac{\sigma_{23}^{2}-\sigma_{22} \sigma_{33}}{S_{23}^{2}}+\frac{\sigma_{12}^{2}+\sigma_{13}^{2}}{S_{12}^{2}}= \begin{cases}\geq 1 & \text { failure } \\ <1 & \text { no failure }\end{cases}$

4. Compressive matrix failure for

$\sigma_{22}+\sigma_{33}<0\left[\left(\frac{Y_{C}}{2 S_{23}}\right)^{2}-1\right]\left(\frac{\sigma_{22}+\sigma_{33}}{Y_{C}}\right)+\frac{\left(\sigma_{22}+\sigma_{33}\right)^{2}}{4 S_{23}^{2}}+\frac{\sigma_{23}^{2}-\sigma_{22} \sigma_{33}}{S_{23}^{2}}+\frac{\sigma_{12}^{2}+\sigma_{13}^{2}}{S_{12}^{2}}= \begin{cases}\geq 1 & \text { failure } \\ <1 & \text { no failure }\end{cases}$

5. Interlaminar tensile failure for $\sigma_{33}>0\left(\frac{\sigma_{33}}{Z_{T}}\right)^{2}= \begin{cases}\geq 1 & \text { failure } \\ <1 & \text { no failure }\end{cases}$

6. Interlaminar compression failure for $\sigma_{33}<0\left(\frac{\sigma_{33}}{Z_{C}}\right)^{2}= \begin{cases}\geq 1 & \text { failure } \\ <1 & \text { no failure }\end{cases}$

The numerical prediction presents reliable simulations not only in the sense of the geometry of the numerical model which has been realized by a unique structure in shell elements but also with the criterion of damage related to this region. In other words, no interface between the folds or between the fibers and the matrix. Add to this that our search result was in the overall response of the structure under loading and its failure load. So the numerical computation parameters were in agreement with the convergence of computation, which allows us moreover to go to the evaluation of several geometrical parameters hardly supported by numerical computations. The parameters introduced in the ABAQUS calculation code are:

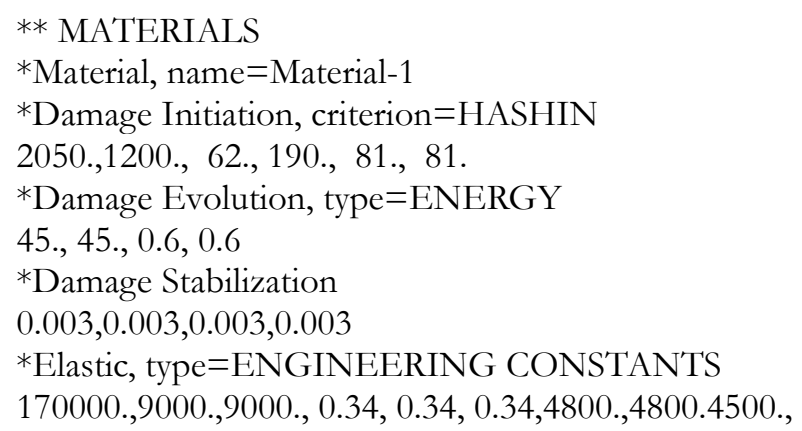

\section{DESCRIPTION OF MODEL GEOMETRY AND MATERIAL PROPERTIES}

$\mathrm{T}$ he geometric finite element model is shown in Figure 1. Material and strength properties for the composite patch material (carbon / epoxy) are shown in Tables 1, 2 and 3 respectively.

The laminated carbon / epoxy composite sheet having the following dimensions: Height $\mathrm{H}=140 \mathrm{~mm}$, width $\mathrm{w}=$ $50 \mathrm{~mm}$, thickness e $=2 \mathrm{~mm}$. A single circular shape with only one dimension of the notch is taken for each stacking sequence. These plates are subjected to an imposed displacement, equal to $2 \mathrm{~mm}$. The modification is positioned around the notch to reinforce and reduce the tension of the damaged area in the course of loading (figure 1). The dimensions of the thicknesses of this modification are according to the volume fraction of fiber and which are as follows: $0.25 \mathrm{~mm}$ for a fraction of $50 \%, 0.2 \mathrm{~mm}$ for a fraction of $70 \%$ and $0.125 \mathrm{~mm}$ for a fraction of $90 \%$.

In the tensile behavior, the fixing and loading conditions consist in fixing the structure at one edge in the vertical and longitudinal direction and a traction displacement on the opposite edge, the same thing in the torsional behavior except that the loading is in rotation around the center of the plate. In the case where both types of loading are applied, traction and rotation must be in the same direction. 
The elastic and carbon resistance properties of the epoxy are chosen from the library of the CADEC [19] which determines, according to the volume fraction, the properties of the carbon / epoxy composite, and which allows us to calculate the resistance parameters by changing the thickness.

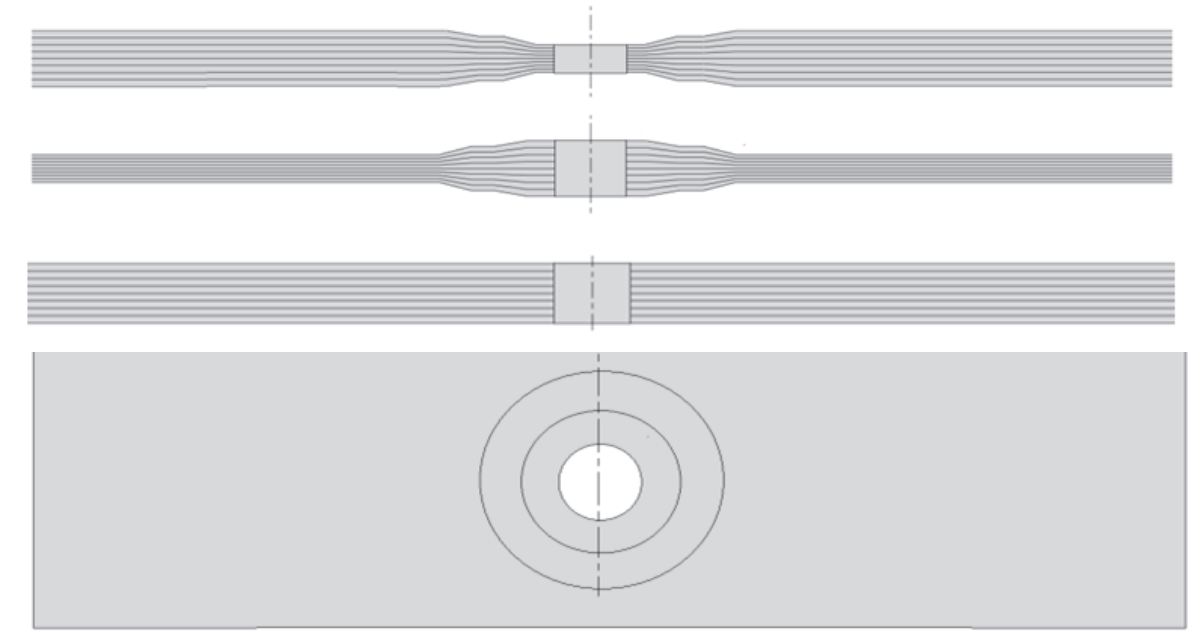

Figure 1: Geometrical modification of the composite plate

\begin{tabular}{lllll}
\hline $\mathrm{E} 1=170000 \mathrm{MPa}$ & $\nu 12=0.342$ & $\mathrm{G} 12=4800 \mathrm{MPa}$ & $\mathrm{XT}=2050$ & $\mathrm{YT}=62$ \\
$\mathrm{E} 2=9000 \mathrm{MPa}$ & $\nu 13=0.342$ & $\mathrm{G} 13=4800 \mathrm{MPa}$ & $\mathrm{XC}=1200$ & $\mathrm{YC}=190$ \\
$\mathrm{E} 3=9000 \mathrm{MPa}$ & $\nu 23=0.342$ & $\mathrm{G} 23=4500 \mathrm{MPa}$ & $\mathrm{SL}=81$ & $\mathrm{ST}=81$ \\
\hline
\end{tabular}

Table 1: For a $65 \%$ fraction and $0.25 \mathrm{~mm}$ thickness [20].

\begin{tabular}{lllll}
\hline $\mathrm{E} 1=195000 \mathrm{MPa}$ & $\nu 12=0.32$ & $\mathrm{G} 12=8167 \mathrm{MPa}$ & $\mathrm{XT}=2500$ & $\mathrm{YT}=74$ \\
$\mathrm{E} 2=13450 \mathrm{MPa}$ & $\nu 13=0.32$ & $\mathrm{G} 13=8167 \mathrm{MPa}$ & $\mathrm{XC}=1500$ & $\mathrm{YC}=224$ \\
$\mathrm{E} 3=13450 \mathrm{MPa}$ & $\nu 23=0.32$ & $\mathrm{G} 23=7137 \mathrm{MPa}$ & $\mathrm{SL}=90$ & $\mathrm{ST}=90$ \\
\hline
\end{tabular}

Table 2: For a $75 \%$ fraction and a $0.2 \mathrm{~mm}$ thickness.

\begin{tabular}{lllll}
\hline $\mathrm{E} 1=221500 \mathrm{MPa}$ & $\nu 12=0.31$ & $\mathrm{G} 12=13540 \mathrm{MPa}$ & $\mathrm{XT}=3000$ & $\mathrm{YT}=82$ \\
$\mathrm{E} 2=21670 \mathrm{MPa}$ & $\nu 13=0.31$ & $\mathrm{G} 13=13540 \mathrm{MPa}$ & $\mathrm{XC}=2200$ & $\mathrm{YC}=236$ \\
$\mathrm{E} 3=21670 \mathrm{MPa}$ & $\nu 23=0.31$ & $\mathrm{G} 23=11790 \mathrm{MPa}$ & $\mathrm{SL}=97$ & $\mathrm{ST}=97$ \\
\hline
\end{tabular}

Table 3:For a fraction of $85 \%$ and thickness of $0.125 \mathrm{~mm}$.

E: Young's modulus, v: Poisson's ratio, G: shear modulus

XT: Longitudinal tensile strength, XC: Longitudinal compressive strength, YT: Transverse tensile strength YC: Transverse compressive strength, SL: Longitudinal shear strength, ST: Transverse shear strength

Different ply orientations of the composite adherent are considered in this study to investigate their effect on the failure load. The value of $\theta$ (orientation angle) is taken from the longitudinal direction of the structure (x-axis) and varied from $0^{\circ}$ to $90^{\circ}$ (Table 1,2,3) with step of $15^{\circ}$. Then, in the second case, some modifications were introduced and presented in Fig.8. All layers have the same matrix (epoxy) and the same fiber materials (carbon). 


\begin{tabular}{cccccc}
\hline & 1 & 2 & 3 & 4 & 5 \\
\multirow{2}{*}{ Plies sequences } & $(0) \mathrm{s}$ & $(0 /-15 / 15 / 90) \mathrm{s}$ & $(0 /-30 / 30 / 90) \mathrm{s}$ & $(0 /-45 / 45 / 90) \mathrm{s}$ & $(0 /-60 / 60 / 60 / 90) \mathrm{s}$ \\
\hline
\end{tabular}

Table 4: The sequences of the plies used.

The different configurations of the architecture composite structures are proposed to evaluate the behavior of their damaged. First, we used a structure plate with the same thickness and natureof fiber but the thickness of the layers changes around the notch simultaneously with different other parameters and with different orientations (Figure 1).

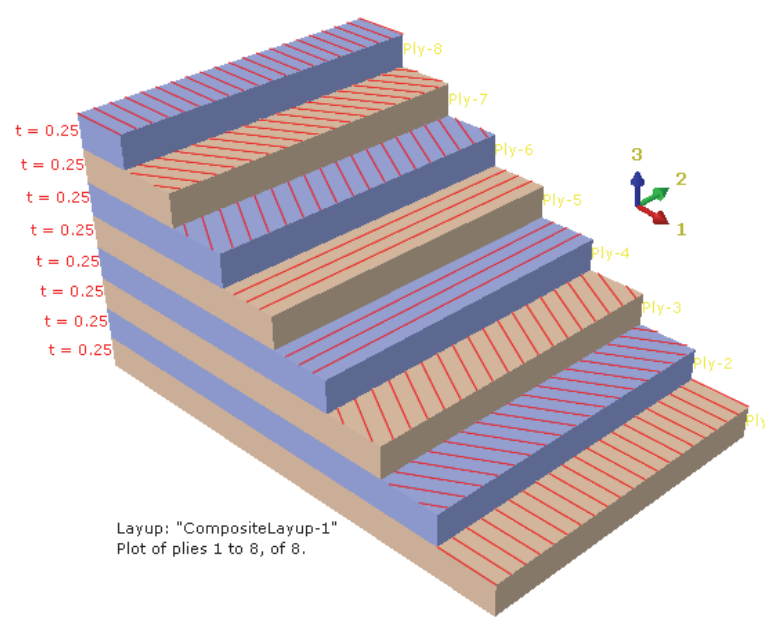

Figure 2: The Stacking sequence of composite used.

For the configuration $\mathrm{n}^{\circ} 1$ of the laminate, the thickness of all layers is identical of each layer and equal to $0.25 \mathrm{~mm}$ (Fig. 1). For the configuration $n^{\circ} 2$ and $n^{\circ} 3$, the thicknesses of the several layers of the laminate are not identical; we can found two models; when the thickness increase progressively around the notch from $0.125 \mathrm{~mm}$ to $0.25 \mathrm{~mm}$ going through 0.20 $\mathrm{mm}$ (Fig. 3), we call it configuration $\mathrm{n}^{\circ} 2$ and when the thickness is decrease around the notch from $0.25 \mathrm{~mm}$ to $0.125 \mathrm{~mm}$ going through $0.20 \mathrm{~mm}$ (fig.3), we call it configuration $\mathrm{n}^{\circ} 3$.
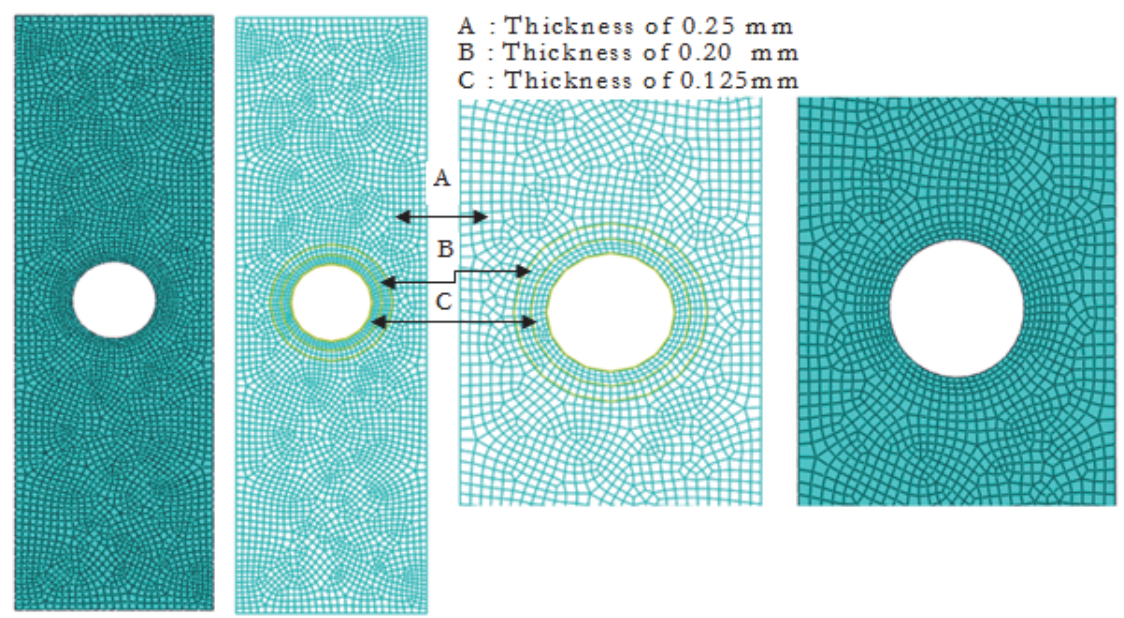

Figure 3: Detail of the mesh of each Area.

In this analysis, the mesh of the structure is refined around the area of the notch in order to accurately capture the area of damage. To simulate the damage in the plate, the linear behavior of the composite was presented using S4R shell elements (zero thickness) or the thickness of the structure was introduced into the properties of the composite. The number of elements is 13428 elements. The Hashin criterion is implemented in the structure studied, and for each modification of 
the properties of the structure, the same number of elements is used. Figure 3 shows a detail of the mesh used for the calculations.

\section{RESULTS AND ANALYSIS}

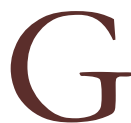

enerally in structures, the geometric discontinuity such as the notch, has a weakness that quickly promotes their damage. These structures do not only undergo traction, which is the most dangerous solicitation, but also other loads that can undoubtedly accelerate their failure. During loading, the participants (stacking sequence / hybrid / geometric modification) play a determining role in the values of the resistance and the structural reaction to loading, are the parameters that have been evaluated in this work.

It is by design that these cuts impose their existence in the structures, where often their damage will begin. From this problem, it is essential to look for a solution that takes the objective of reinforcement in order to delay the damage. Referring to the work of Benzaama[9].where the shape and size of the notch has been widely studied.

In this study, only the reinforcement with the circular shape around the circular notch is limited by evaluating only the competition effect between the reduction of the thickness and the increase of the fiber volume fraction.

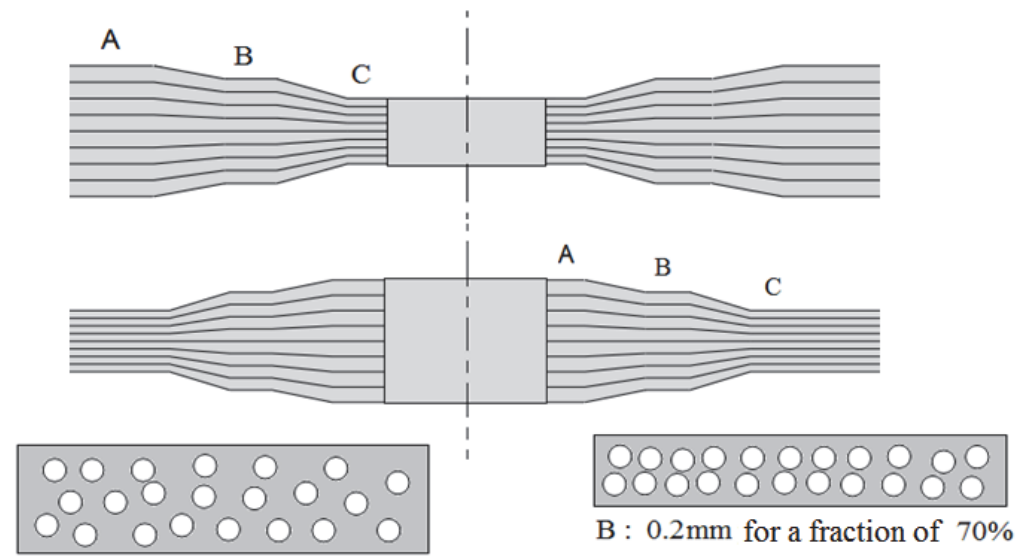

A : $0.25 \mathrm{~mm}$ for a fraction of $50 \%$

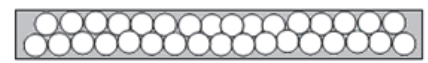

C : $0.125 \mathrm{~mm}$ for a fraction of $90 \%$

Figure 4: Geometrical modification around the notch.

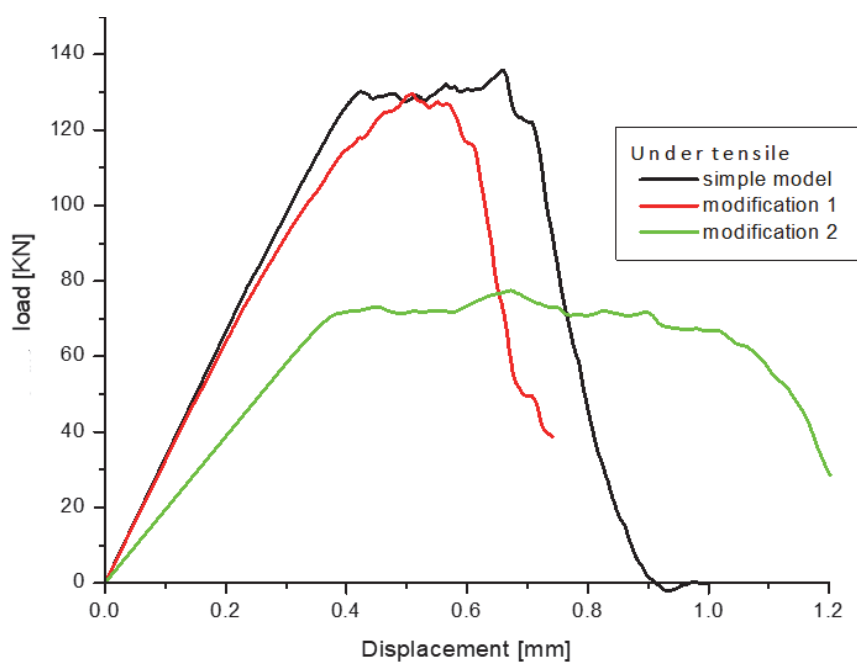

Figure 5: Load displacement curve under tension loading.

We made two changes: first when the thickness decreases and second when the thickness increases. The continuity of the fibers in the zones modified by a change of volume fraction and effectively of the thickness is ensured numerically by a change in the properties of rigidity and fracture of the composite if not, the calculation will take a discontinuity of the 
fibers. The use of the Computer Aided Design Environment for Composites (CADEC 2014) will allow us in advantage to have the stiffness properties as well as the strength of the composite when loading at the notch.

\section{Effect of loading type and geometric modifications on the behavior damage of the laminate plate notching}

Often researchers are interested in structures that are subjected to loadings only in traction to determine their behavior. What is new in this part of the work is to add, not only another rarely studied behavior, but also to associate these two types of loading traction with rotation and likewise to make a comparison between these different types of loading in order to have a prediction of the damage of a notched laminate structure.

First, each geometric model takes are evolution to the predicted damage that is presented by the load-displacement curves, these geometric models are:

- simple model without modification, we took it as a witness in order to compare it with the other models those of renamed modifications 1 and 2.

- for modification 1; we increased the thickness with the decrease in the volume fraction near the notch to keep the fiber continuity numerically.

- for modification 2; it is the opposite of the modification 1, we decreased the thickness and increased the volume fraction in the vicinity of the notch.

The proposition of these geometric shapes with the simple form allows us to better compare and better understand how the damage occurs in nonlinear (geometric and property) situations.

Figure 5 shows the reaction of the structure to the imposed loading type traction and with circular notch. It can be seen that the effect of the proposed geometries is directly proportional to the strength of the structure; for geometric modification 1 where we have a reduction of the thickness at the notch which has a reduction which remains very small, the change of the load response of the structure appears beyond a displacement of $0.2 \mathrm{~mm}$. Modification 2 presents a whole change in the response to loading and subsequently in its resistance levels; less resistance more elongation in the structure.

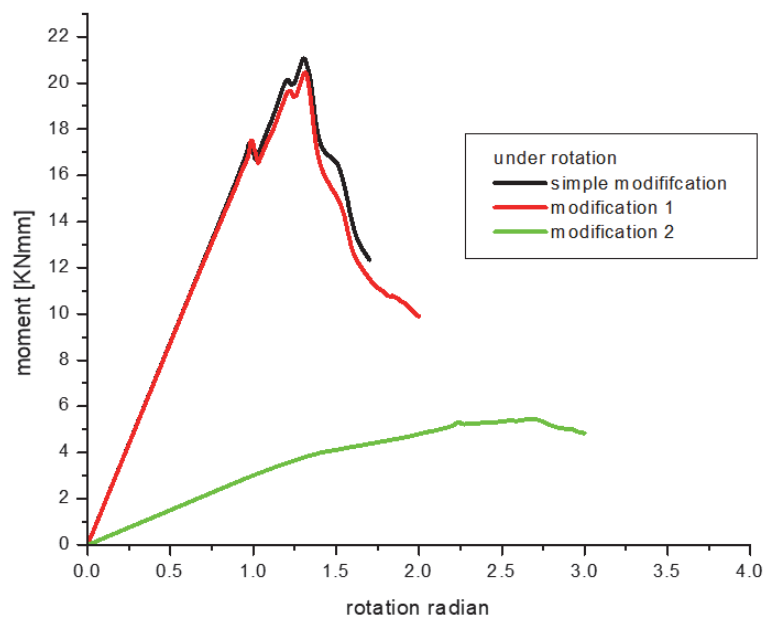

b)

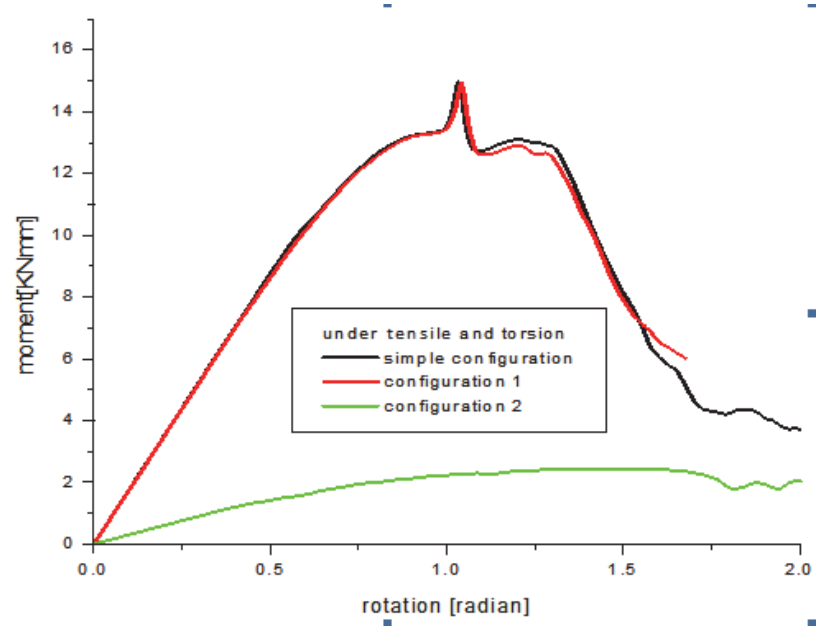

Figure 6:(a) Load displacement curve under torsion loading; (b) Load displacement curve under mixed loading.

In the Figure 6-a, the proposed reinforcements not only increase the rigidity of the structure but also the resistance to damage. The proposed reinforcing capacity and in particular the modification 2 does not have any advantage in the resistance to damage. While the modification 1 is more resistant if and only if, the size of modification widens or is optimized, the same remarksare noted in the two types of loading applied; traction and torsion. On the other hand, what is different in the results is that the response to the loading for the behavior in torsion and purely linear with the fast damage.

Figure 6-b shows the mixed stress of the notched plate: traction and rotation with the same pitch not to favor one over the other. It is also noted that the capacity of reinforcement by the proposed modifications on the structural resistance is conditioned much more by the type of loading than by the geometrical modifications. 
Effect of stacking sequence and composite bybrid of the plate notched on the behavior damage:

In this part of the study we are interested in the stacking effect of the structure itself and the change of nature of the fiber in some folds of laminates as a determining parameter that can give more resistance to the damage of the structure notched. The load transfer in the structure around the notch is ensured by its rigidity which is ensured by the orientation of the fibers and thus the objective is to evaluate the value of the breaking load by the modification of the stiffness of the composite (stacking sequence).

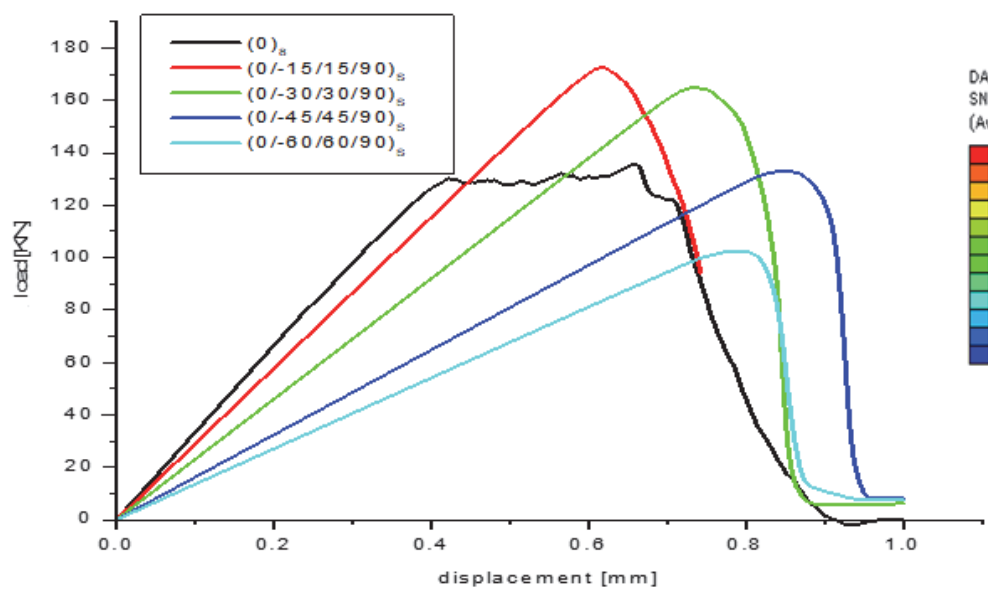

(a)

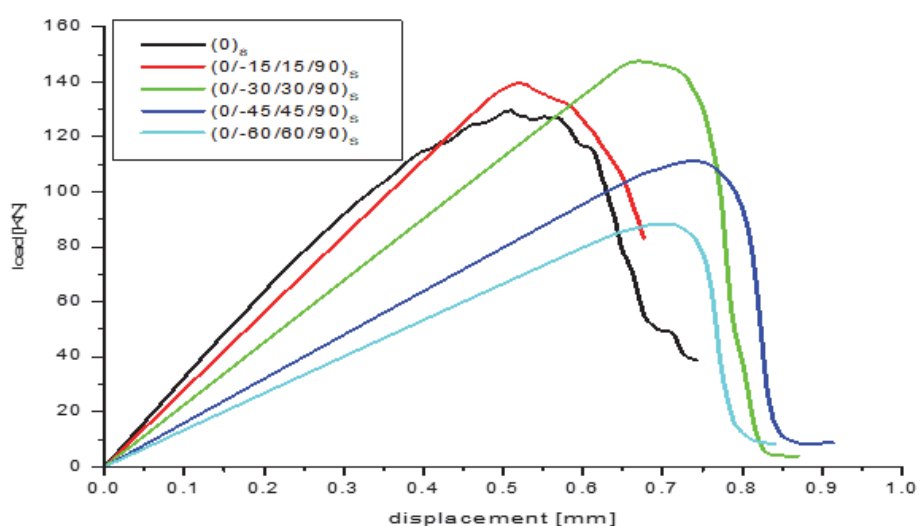

(b)

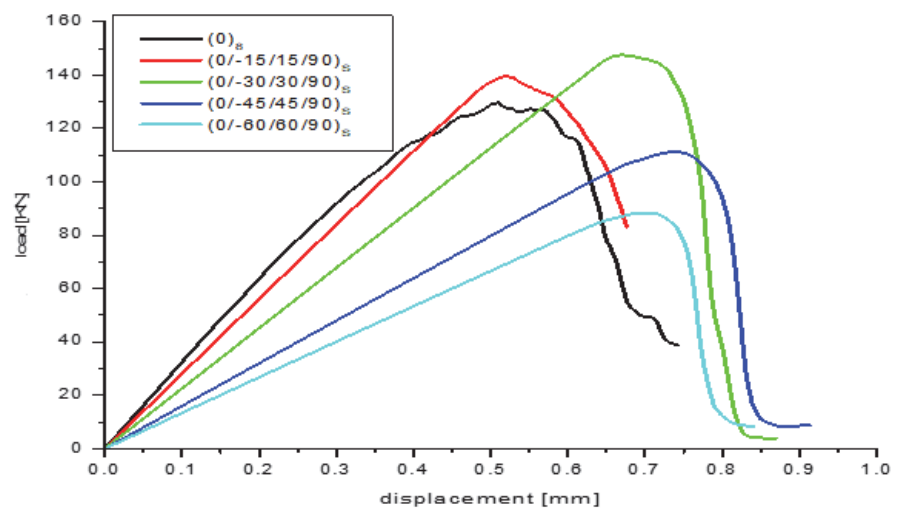

$0^{\circ}$

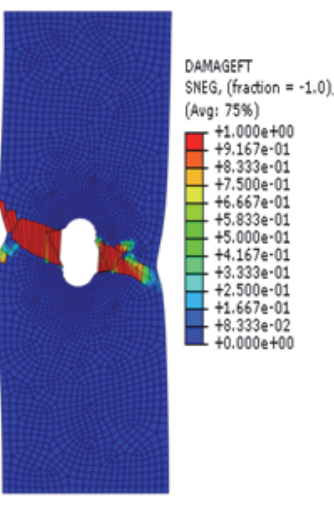
(Avg: 75\%) $+1.000 \mathrm{e}+00$
$+9.167 \mathrm{e}-01$
+ $+8.333 \mathrm{e}-01$ $+7.500 \mathrm{e} \cdot 01$
$+6.667 \mathrm{e}-01$
$+5.833 \mathrm{e}^{-01}$
+5 $+5.833 \mathrm{e} .01$
$+5.000 \mathrm{e}-01$
$+5.167 \mathrm{e}-01$ $+4.167 \mathrm{e} \cdot 01$
$+3.333 \mathrm{e} .01$
$+2.500 \mathrm{e}-01$ $+1.667 \mathrm{e} \cdot 01$ $+1.633 \mathrm{e} \cdot 02$
$+0.000 \mathrm{e}+00$
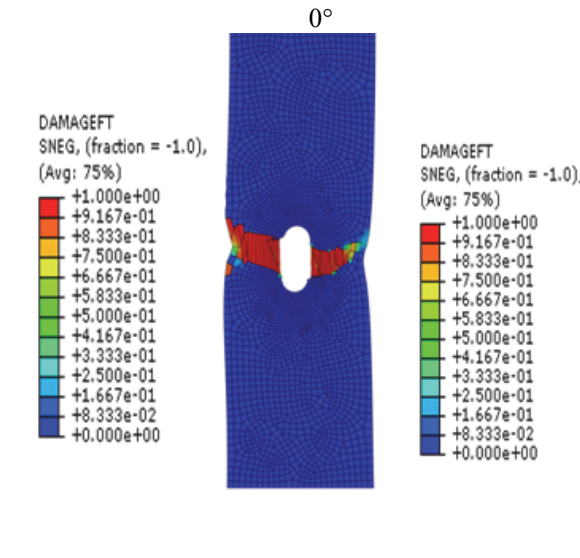

$60^{\circ}$

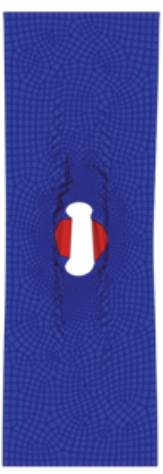

$0^{\circ}$

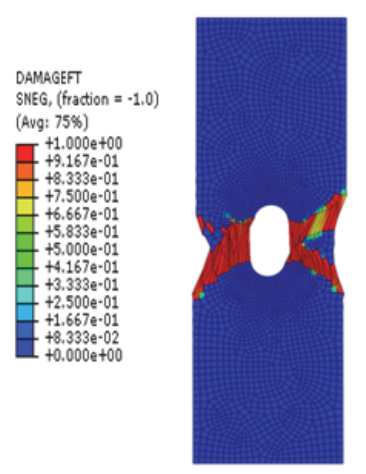

$60^{\circ}$

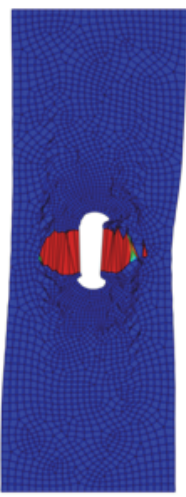

(c)

Figure 7:(a) Load displacement curve under tension loading of simple geometry;(b) Load displacement curve under tension loading of modification1;(c) Load displacement curve under tension loading of modification 2. 
These figures7-a-b-c show the effect of stacking on the resistance of these geometrically modified plates at the notch under the traction load. The catches are presented for each case and only for the damage of the fibers in tension which are responsible for the overall damage of the structure. For all cases of modification, we notice a linear behavior until the damage. For the simple geometry with the stacking effect we notice different values in the damage force as in the displacement at break. These stacks significantly improve the overall strength throughout the structure and particularly at the notch relative to the 0 and 1 orientation stacks. The stacks of 15 and 30 are more resistant than those of 45 and 60, which remain remarkable for the geometry of the first modification 1 with a different magnitude, except for the second modification which largely favors the stacking effect of all fiber orientation angles. In the end, we can see that with the geometric modifications and its optimized stacks we can obtain a higher resistance than the structures without modification.

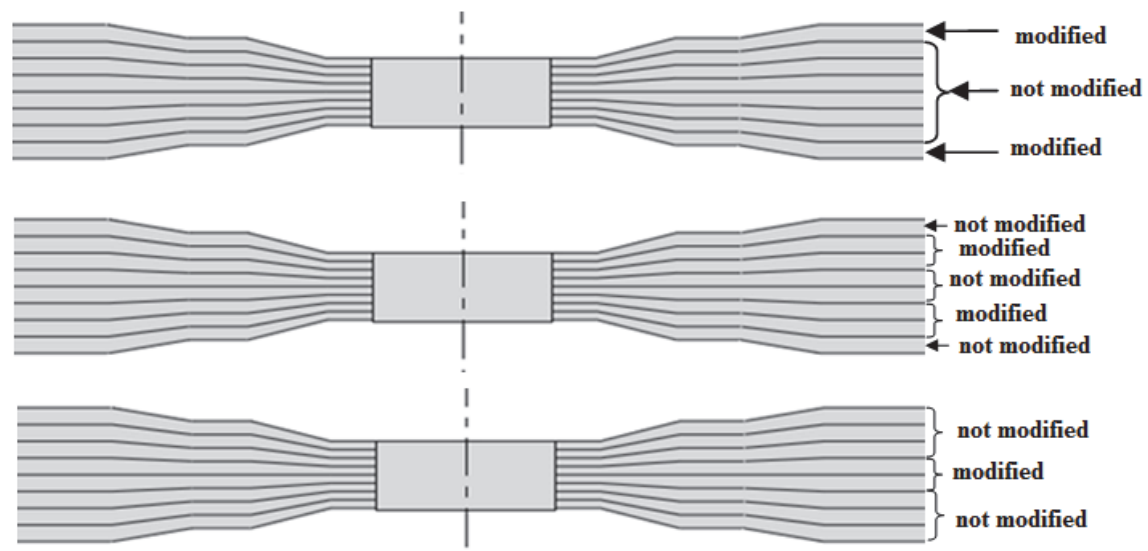

Figure 8: Reinforcement of the thickness of some layers (the modifications are symmetric in the other side).

In this part of our study, we modified the mechanical properties of different layers by choosing a hybrid composite as shown in the following stacking sequences:
$(0 /-30 / 30 / 90) \mathrm{s}$
$\left(0_{\mathrm{R}} /-30 / 30 / 90\right) \mathrm{s}$
$\left(0 /-30_{\mathrm{R}} / 30_{\mathrm{R}} / 90\right) \mathrm{s}$
$\left(0 /-30 / 30 / 90_{\mathrm{R}}\right) \mathrm{s}$

where $\mathrm{R}$ stays for the reinforced thickness of layers in the composite.

We change only the thickness of two layers which have the same fiber orientations for the three stacking sequences of structure (Fig. 8). Hence, we get 8 plies of composite.

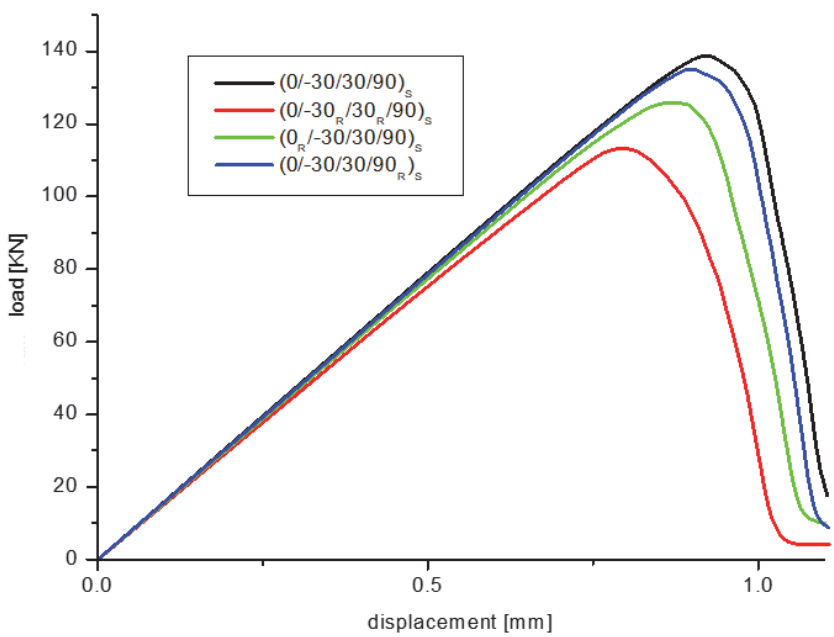

(a)

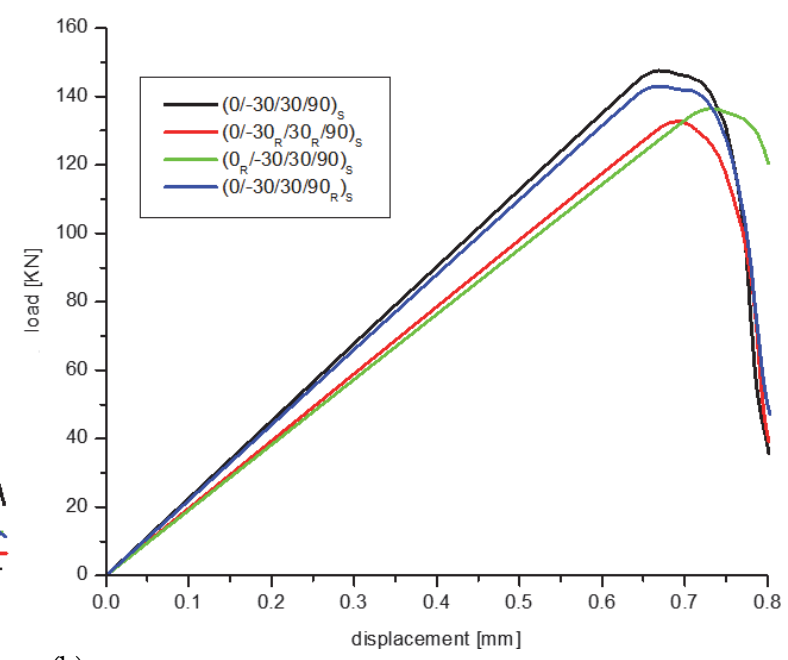

(b)

Figure 9: (a) Load displacement curve under tension loading of hybrid mod1. (b) Load displacement curve under tension loading of hybrid $\bmod 2$. 
In figure 9, force / displacement curves for structures with modification 1 and 2 have been presented with the stacks which each have a high optimized resistance $\left(15^{\circ}\right.$ and $\left.60^{\circ}\right)$. Subsequently, the thickness of the folds, which have the same fiber orientations for each case, has been reinforced as an evaluative parameter, which makes it possible to have their effects on the resistance of the structure. Note that for the two curves, the reinforcement $0^{\circ}$ and $90^{\circ}$ folds have significant values than other angles except those without modification.

\section{CONCLUSION}

7 his work has demonstrated the effectiveness of a $2 \mathrm{D}$ numerical approach with the use of Hashin criterion of damage and with shell elements in laminated composite structures notches. It is also demonstrated the effectiveness of the reinforcement by geometric modifications that summarize our objective.

- The use of the Hashin criterion gives the advantage of analyzing the damage of composite structures with complex geometries.

-The geometrical propositions studied can be accompanied by several parameters that make them more useful in the resistance of notched composite structures.

- The value of the failure load is influenced by the type of the load applied and impalement sequence.

-The introduced changes present a change in the response of the structure to the changes.

- The carbon/epoxy composite absorbs better the stress than the aramid/epoxy and therefore a reduction in the value of load is observed.

-The damage value and the propagation path follow the orientation of the fibers in the stress concentration zone.

- The rack birth and its propagation depend directly on the fiber orientation at of the notch tip.

\section{REFERENCES}

[1] ABAQUS, Abaqus Version (2009). 6.9 Documentation. Providence, RI: Dassault Systems Simulia Corporation.

[2] Bureau of Accident Investigation. (1989). Aircraft Accident Report: Aloha AirlinesFlight 243 Boeing 737-200. National Transportation and Safety Office. Available at: https://www.faa.gov/about/initiatives/maintenance_hf/library/documents/media/human_factors_maintenance/air craft_accident_report--aloha_airlines.flight_243.boeing_737-200.n73711. near_maui.hawaii.april_28. 1988.

[3] Ponces Camanho, P. (2002). Failure criteria for fibre-reinforced polymercomposites, DEMEGI.

[4] Lu, J., Lieurade, H P., Tehniques de l'Ingénieur, Concentration de contraintes, Génie mécanique BM 5, 40, pp. 1-24.

[5] Madani, S., Touzain, X., Feaugas, S., Cohendouz, M., Ratwani, M. (2010) Experimental and numerical study of repair techniques for panelswith geometrical discontinuities. Computational Materials Science (48), pp.83-93. DOI: $10.1016 /$ j.commatsci.2009.12.005

[6] Mokhtari, M., Madani, K., Benzaama, H., Malarino, S.(2017).Effects of the composite stacking sequence on the failure load of the single lap bonded joint. Journal of Theoretical And Applied Mechanics, 55(4), pp. 1257-1268.

[7] Mokhtari,M., Madani, K., Belhouari ,M., Touzain, S., Feaugas, X., Ratwani ,M .(2013).Effects of composite adherend properties on stresses in double lap bonded joints. Materials and Design, 44, pp. 633-639.

DOI: http:/ /dx.doi.org/10.1016/j.matdes.2012.08.001.

[8] Ait Kaci, D., Madani, K., Mokhtari, M., Feaugas,X. ,Touzain,S.(2017) .Impact of composite patch on the J-integralin adhesive layer for repaired aluminum plate. Advances in Aircraft and Spacecraft Science,4(6),pp. 679-699.

[9] Benzaama, A., Mokhtari,M., Benzaama, H., Gouasmi, S., Tamine, T. (2018).Using XFEM technique to predict the damage of unidirectional CFRP composite notched under tensile load. Advances in Aircraft and Spacecraft Science,5(1), pp. 129-139.

[10] Donadon, M. V., De Almeida, S F M., Arbelo,M A., Orúe, A B. (2009). A three-dimensional ply failure model for composite structures. International Journal of Aerospace Engineering. DOI: 10.1155/2009/486063.

[11] Linde, P., De Boer, H. (2011). Behaviour of solid like shell elements in simulation of composites in aircraft structures.16th International Conference on Composite Structures ICCS 16 A. J. M. Ferreira (Editor) FEUP, Porto, Portugal.

[12] Elangovan, P. (2012). A Study on Solid and Shell Material Model in Stamping Simulation. Stamping Simulation Engineer Valeo India Private LimitedBlock - A, 4th Floor, TECCI Park No. 176 Rajiv Gandhi Salai Sozhanganallur Chennai ,pp.600-119. India, HTS. 
[13] Guo ,Y . (2000).Eight-Node Solid Element for Thick Shell Simulations, Livermore Software Technology Corporation Livermore, California, USA, 8, pp. 46.

[14] Barberon, E., Shahbazi, M .(2017). Determination of Material Properties for ANSYS Progressive Damage Analysis of Laminated Composites. Composite Structures, 176, pp. 768-779.

[15] Davila,C G., Camanho, P P., Rose, C A .(2005). Failure Criteria for FRP Laminates. Journal of composite materials. DOI: $10.1177 / 0021998305046452$.

[16] ABAQUS finite element programs. ABAQUS iStandard 5.6. Hibbitt. Pawtucket, RI 028: Karlsson and Sorensen, Inc.

[17] Sokolinsky, V. (2013). Using Failure Criteria for Unidirectional Fiber Composite in Abaqus, Simulia.

[18] Pederson, J. (2006).Finite Element Analysis of Carbon Composite Ripping using Abaqus. Masters diss, Clesmo University. Available at: https://tigerprints.clemson.edu/cgi/viewcontent.cgi?article=1512\&context=all_theses.

[19] Computer Aided Design Environment for Composites, CADEC 14.1.6521.18183. Available at: http://en.cadec-online.com/.

[20] Trigo, J.(1996). Dimentional stability characterization of carbon fiber with epoxy and cyanate ester resin laminates due to moisture Absorption.Space craft structures. materials and mechanical engineering, Proceedings of the Conference held by ESA, CNES and DARA in Noordwijk, Paris. 